\title{
True or not? Chinese government quotes WHO Chief statement "that there is no Evidence that the New Coronavirus Novel COVID 19 was Produced in the Laboratory" But US Government Says, "that the Coronavirus Originated from a Laboratory in China despite the Lack of Evidence"
}

\author{
Dr Ahsan Siddiqui, M.D, M.S.P.H (UK)* \\ Department of Quality Management \& Patient Safety Department, General Directorate of Health, Riyadh Saudi Arabia \\ *Corresponding author: Dr Ahsan Ali Siddiqui, Consultant Epidemiologist, Quality Management \& Patient Safety \\ Department, General Directorate of Health, Riyadh Saudi Arabia
}

\section{ARTICLE INFO}

Received: May 05, 2020

Published: 慧 May 27, 2020

Citation: Ahsan Ali Siddiqui. True or not? Chinese government quotes WHO Chief statement "that there is no Evidence that the New Coronavirus Novel COVID 19 was Produced in the Laboratory" But US Government Says, "that the Coronavirus Originated from a Laboratory in China despite the Lack of Evidence". Biomed J Sci \& Tech Res 27(5)-2020. BJSTR. MS.ID.004575.

Keywords: COVID-19 novel corona virus; Global pandemic; Wuhan research Laboratory; Biosafety level 4 (BSL lab) in the Wuhan Institute of Virology; World health organization (WHO); A greater horseshoe bat; Centre of Disease control (CDC) China

\section{Abstract}

Background and Objective: The main objective of this Article is to investigate and find out after reviewing 23 referenced News articles and published papers to gather evidence that novel corona virus COVID-19 was accidentally leaked in the community. Eight Published Newspaper Articles were carefully selected to find out the documentary and visual evidence that novel corona virus COVID-19 was accidentally leaked from the Wuhan research Laboratory in China.

Methods: Literature review and then critical analysis of the 23 News Articles and published papers in different Newspapers and scientific journals at the same time. Search for the evidence is provided by carefully selected 8 News Articles which give details that novel corona virus COVID-19 was produced and accidentally leaked by Wuhan research laboratory. A table was developed where 8 News articles was searched and compared for the evidence of leak of novel corona virus COVID-19.

Results: Upon reviewing the carefully selected 8 News Articles only two articles provide the picture and documented evidence that may be accidentally in the Wuhan laboratory the studied novel corona virus got out of laboratory.

Conclusion: By looking at the results of the data table, data analysis and diagrammatic presentation $25 \%$ of the News articles provides some evidence and $75 \%$ of the news articles did not provide any evidence. The evidence we are looking at that Wuhan laboratory is clearly responsible for accidentally leaking the novel corona virus COVID-19 in the community.

\section{Introduction}

Emerging infectious diseases are a major challenge in the $21^{\text {st }}$ century. In recent years worldwide outbreaks of Ebola and Middle East Respiratory Syndrome caused great health and economic losses. The ongoing new coronavirus pneumonia, Corona Virus Disease COVID-19 outbreak is becoming a global public health problem. The COVID-19 outbreak is highly similar to the severe acute respiratory syndrome (SARS) outbreak that occurred in 2003 both outbreaks were caused by new coronaviruses during time periods overlapping with the Chinese Spring Festival (Chen ZeLiang, Zhang Qi, Lu Yi, et al, 2020).On December 31,2019, the Wuhan Municipal Health Committee reported 27 cases of pneumonia with an unknown cause, and many cases were traced to the Wuhan 
Southern China Seafood Market which was subsequently closed on January 1 2020.0n January 72020 laboratory tests showed that the pathogen causing the previously unexplained pneumonia was a new type of coronavirus this pneumonia was then officially named COVID-19 by the World Health Organization. The COVID-19 outbreak started in Wuhan and spread rapidly to other provinces and countries [1].

As of January 30 2020, a total of 34 provinces and regions in China had reported 9692 cases and nearly all imported cases were derived from Wuhan in Hubei province (Chen Ze-Liang, Zhang Qi, Lu Yi, et al, 2020). On 10 January 2020 a new coronavirus causing a pneumonia outbreak in Wuhan City in central China was denoted as 2019-nCoV by the World Health Organization. As of 24 January2020 there were 887 confirmed cases of $2019-\mathrm{nCoV}$ infection including 26 deaths reported in China and other countries. Therefore, combating this new virus and stopping the epidemic is a matter of urgency. Here we focus on advances in research and development of fast diagnosis methods, as well as potential prophylactics and therapeutics to prevent or treat 2019-nCoV infection. At the end of December2019 the Wuhan Municipal Health Commission reported the outbreak of viral pneumonia caused by an unknown pathogen in Wuhan China(Fei Yu, Lanying Du, David Ojcius et.al, 2020) Subsequently the unknown pathogen was identified as a novel coronavirus denoted as $2019-\mathrm{nCoV}$ by the World Health Organization on 10 January 2020.

On 12 and 13 January 2020, the full genomic sequence of 2019nCoV denoted WIV0 4 strain (GISAID accession no. EPI_ISL_402124) was released with about $82 \%$ homology to that of SARS-CoV Tor 2 (GenBank accession no. AY274119) and bat SARS-like coronavirus WIV1 (bat SL-CoV-WIV1, GenBank accession no. KF367457.1)(Fei Yu, Lanying Du, David Ojcius et.al, 2020). US Secretary of State
Mike Pompeo said Sunday there was enormous evidence that the coronavirus pandemic originated in a laboratory in Wuhan China echoing a claim made by President Donald Trump earlier this week (France 24, 2020) [2].These are not the first times that we've had a world exposed to viruses as a result of failures in a Chinese lab Pompeo added pointing at China's history of running substandard laboratories. Though highly critical of China's handling of the matter Pompeo declined to say whether he thought the virus had been intentionally released. Beijing has suggested the US military might have brought the virus to China and Trump has said China failed to alert the world to the risks in a timely and transparent fashion (France 24, 2020).

Worrying photographs of scientists handling bat samples have been deleted from the website of the institute blamed for the coronavirus pandemic. The images which reveal a shocking lack of safety were taken down by the Wuhan Institute of Virology after diplomats and scientists raised the alarm about its work(The sun UK, 2020).During interactions with scientists at the Wuhan Institute of Virology laboratory they noted the new lab has a serious shortage of appropriately trained technicians and investigators needed to safely operate this high containment laboratory. It was claimed that Covid-19 was developed in the Wuhan lab as China hoped to prove it's greater than the US at battling deadly diseases [3]. One worker admitted being sprayed with bat blood or urine as images showed staff brazenly collecting samples with no face masks or protective suits. Earlier this month photos from the same Wuhan lab showed a broken seal on a store containing 1,500 virus strains including the bat coronavirus linked to the devastating pandemic. Incredibly some scientists didn't even wear gloves as they entered caves to collect fecal bat swab samples beaming for the camera and oblivious to the dangers (The sun UK, 2020) (Figures 1 \& 2).

\section{DAinfy China Daily.}

Folgen

Take a look at the largest \#virus bank in Asia!

Wuhan Institute of Virology in Central China's Hubei province preserves more than 1,500 different strains of virus.

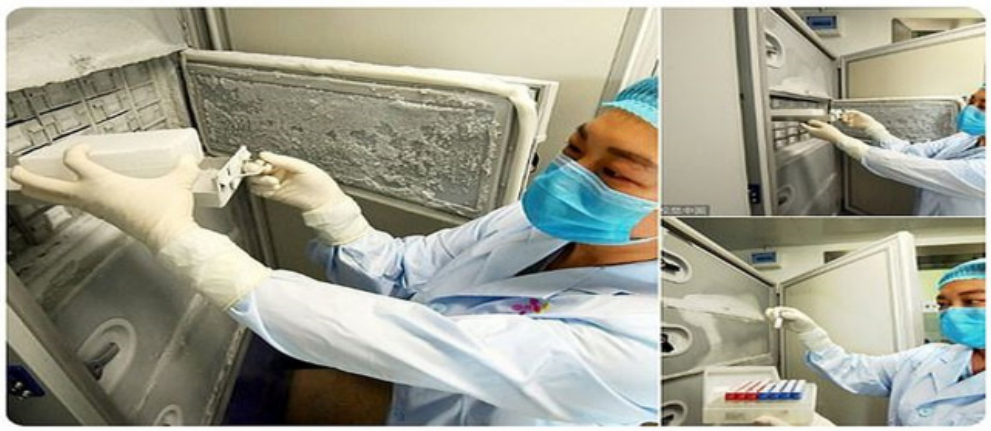

17:15 - 28, Mai 2018

Figure 1: Mirror Coronavirus news, 2020). 




Figure 2: Mirror Coronavirus news, 2020): The Wuhan Institute of Virology linked to the global pandemic.

US President Trump neither confirmed nor denied the report but noted that more and more we are hearing the story and we'll see. We are doing a very thorough examination of this horrible situation that happened the President added. The news channel said that China initially made efforts to cover up the outbreak. Sources also characterized the World Health Organization (WHO) as being part of a coverup from the very beginning the report said (Gulfnews.com world Americas, 2020).Scientists at the Wuhan Institute of Virology have also been considered as possible culprits in a lab leak. In 2018 US officials raised concerns about safety issues at that lab according to diplomatic cables obtained by The Washington Post (Business Insider coronavirus, 2020) [4]. We believe in holding the Chinese government accountable for changes in regulations and policies that can prevent another laboratory accident. In particular we would like to see a nationally unified movement toward transparency so that the world may rest assured in the belief that China will not hide the next pandemic natural or otherwise if it occurs under their jurisdiction. It is vitally important that lab safety is taken seriously in all countries to ensure the survival and continued success of the human race. We do not believe in holding individual lab technicians or employees accountable unless they have demonstrated criminal negligence (Evidence SARS COV-2, 2020) [5-6].

In most accidents procedures and policies are the culprit not individual people. it is widely believed that Patient Zero was infected in Wuhan China with SARS-CoV-2. What is not so certain is where exactly in Wuhan Patient Zero was infected and how he/she was infected. The competing theories are from eating wild animals at the Huanan Seafood Market. From doing work at the Wuhan Institute of Virology which performed gain-of-function research on the original SARS virus. Or from doing work at the Wuhan Centre for Disease Control which performed experiments on and housed many bats known for carrying coronaviruses. Patient Zero would then go on to spread the infection likely asymptomatically and this would eventually cause the pandemic now known as COVID-19 and resulting worldwide lockdown (Evidence SARS COV2, 2020) [7-10]. The Wuhan Institute of Virology, which has Asia's highest-level biosafety lab has been at the centre of controversy with some questioning its possible links with the outbreak of COVID-19.The Huanan Seafood Market has been considered the source of the COVID-19 outbreak in Wuhan (Global times china, 2020). Shi Zhenglia research fellow from the institute whose team was involved in analysing the coronavirus said on her WeChat on February 2 that the 2019 novel coronavirus is a punishment by nature to human's unsanitary lifestyle. I promise with my life that the virus has nothing to do with the lab.

Echoing Shi many experts reached by the Global Times also said that it is impossible that the COVID-19 was made in a lab. The Wuhan institute has the National Biosafety Laboratory finished its construction in January 2015 which is Asia's first Bio-Safety Level 4 Lab (BSL-4). There are less than 20 countries in the world that own BSL-4 labs. China should have more BSL-4 labs in more cities to strengthen the country's capability to study unknown viruses and enhance its ability to deal with major public health emergencies Yang added (Global times china, 2020). US President Trump has said he is going to halt funding to the World Health Organization (WHO) because it has failed in its basic duty in its response to the coronavirus outbreak. He accused the UN agency of mismanaging and covering up the spread of the virus after it emerged in China and said it must be held accountable (BBC News US and Canada, 2020). Had the WHO done its job to get medical experts into China to objectively assess the situation on the ground and to call out China's lack of transparency the outbreak could have been contained at its source with very little death he told reporters. This would have saved thousands of lives and avoided worldwide economic damage. 
Instead the WHO willingly took China's assurances to face value and defended the actions of the Chinese government. The US has by far the highest number of coronavirus cases and deaths worldwide with more than 600,000 cases and 26,000 deaths (BBC News US and Canada, 2020) [11].

\section{Methods}

Literature review and then critical analysis of the 23 News Articles and published papers in different Newspapers and scientific journals at the same time. Search for the evidence is provided by carefully selected 8 News Articles which give details that novel corona virus COVID-19 was produced and accidentally leaked by
Wuhan research laboratory. A table was developed where 8 News articles was searched and compared for the evidence of leak of novel corona virus COVID-19. The article outlines how to engage in the critiquing process and explains how the literature review needs to be assembled to generate a logical and reasoned debate to examine a topic of interest or research in more detail(Katharina Schmidt, Ines Aumann, Ines Hollander et al, 2015) [12-16]. A systematic literature review was conducted by searching the Pubmed and Web of Science databases for articles with the following keywords in their titles or abstracts "Analytical Hierarchy Process," "multicriteria decision analysis," "multiple criteria decision" "stated preference" and "pairwise comparison" [17-21].

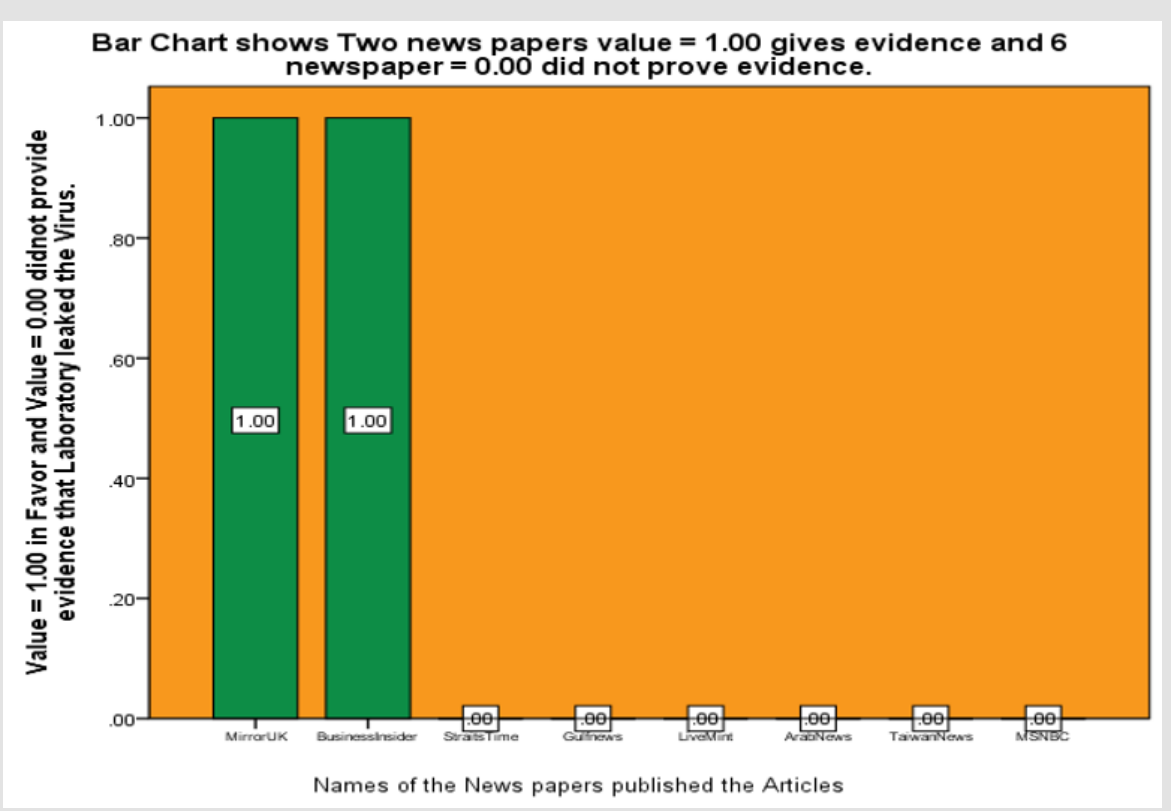

Figure 3.

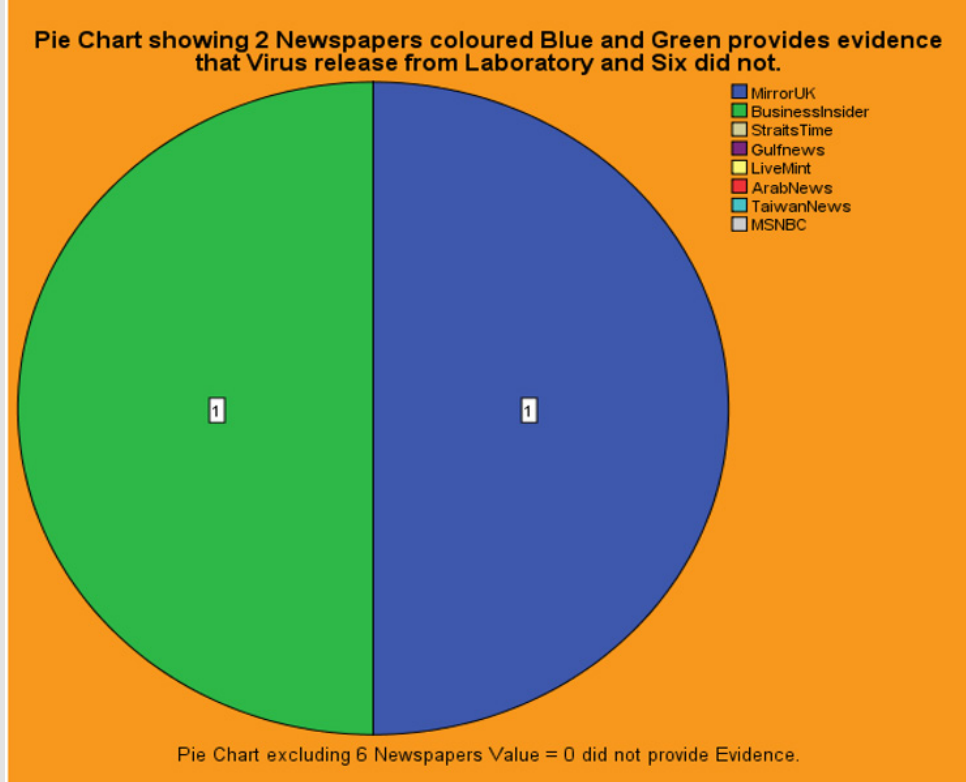

Figure 4. 
In addition, we developed reporting criteria to indicate whether the authors reported important aspects and evaluated the resulting studies' reporting. The systematic review resulted in 121 articles and the number of studies applying AHP has increased since 2005(Katharina Schmidt, Ines Aumann, Ines Hollander et al, 2015). Nowadays, most nurses pre and post qualification will be required to undertake a literature review at some point. Either as part of a course of study as a key step in the research process or as part of clinical practice development or policy. For student nurses and novice researchers it is often seen as a difficult undertaking. It demands a complex range of skills such as learning how to define topics for exploration, acquiring skills of literature searching and retrieval, developing the ability to analyze and synthesize data as well as becoming adept at writing and reporting, often within a limited time scale (Cronin P, Ryan F, Coughlan M, 2008). The purpose of this article is to present a step-by-step guide to facilitate understanding by presenting the critical elements of the literature review process. While reference is made to different types of literature reviews, the focus is on the traditional or narrative review that is undertaken, usually either as an academic assignment or part of the research process. This article examines how to synthesize and critique research literature (Wakefield A, 2015) (Table 1) (Figures 3- 5).

\section{Diagramatic Analysis of 2 Newspapers (25\%) provides evidence and 6 (75\%) didnot provide evidence.}

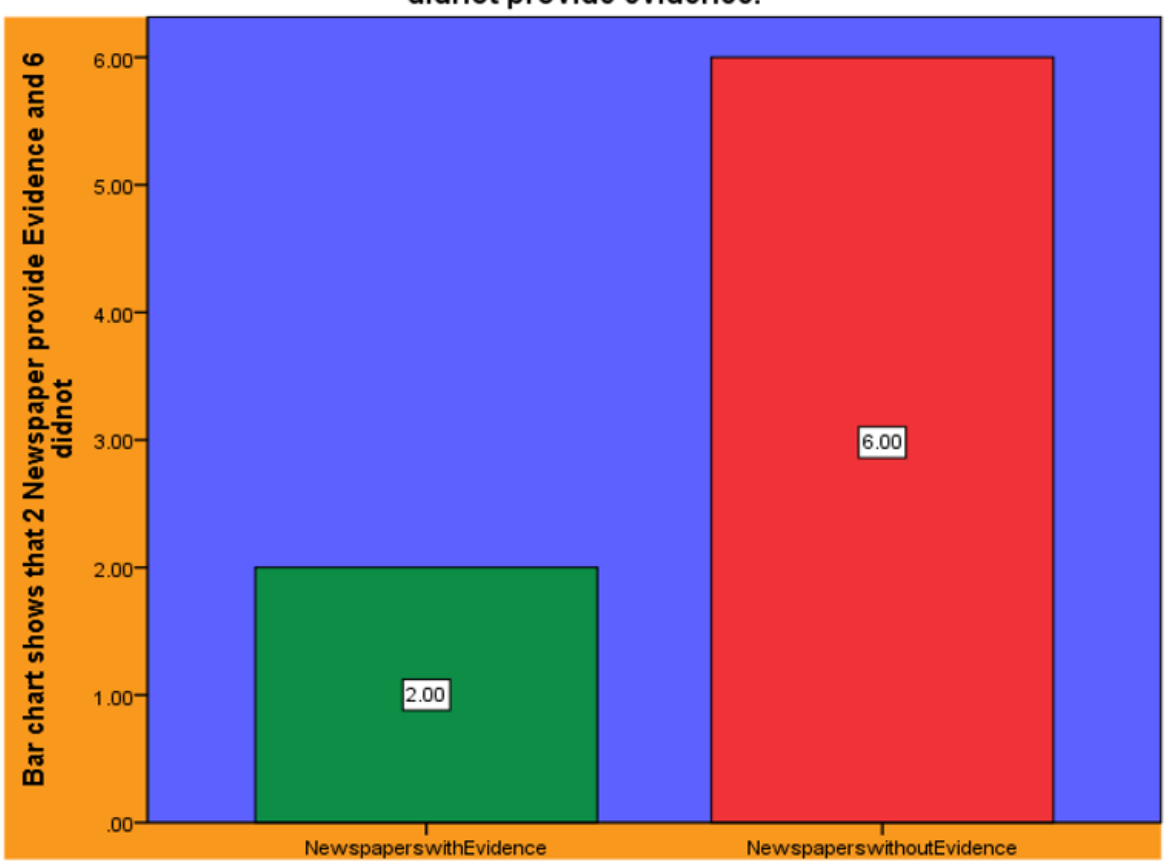

Figure 5.

Table 1: Measure and statistical Analysis:(IBM IBM SPSS Software, 2000).

Literature Review of 8 Published Newspaper Articles and provided evidence that novel COVID-19 Virus was produced in the laboratory.

\begin{tabular}{|c|c|c|}
\hline \multicolumn{2}{|r|}{ Newspaper Articles } & $\begin{array}{c}\text { Provides } \\
\text { Evidence. } Y / N\end{array}$ \\
\hline 1 & $\begin{array}{c}\text { The Straits Times World (2020) Coronavirus pandemic: US pursues theories that virus leaked from Wuhan lab. } \\
\text { Available at: https://www.straitstimes.com/world/united-states/us-pursues-theories-that-virus-leaked-from-wuhan- } \\
\text { lab.(Accessed on 17/04/2020) }\end{array}$ & No \\
\hline 2 & $\begin{array}{l}\text { LiveMint e-paper (2020) Covid-19 virus accidentally leaked by an intern at Wuhan lab suggests US media. Available at: } \\
\text { https://www.livemint.com/news/world/covid-19-virus-accidentally-leaked-by-an-intern-at-wuhan-lab-suggests-us- } \\
\text { media-11587153239725.html (Accessed on 18/04/2020) }\end{array}$ & No \\
\hline 3 & $\begin{array}{c}\text { Mirror Coronavirus news (2020) Photos inside Wuhan lab show broken seal on unit containing bat coronavirus. } \\
\text { Available at: https://www.mirror.co.uk/news/world-news/photos-inside-wuhan-lab-show-21891643 (Accessed on } \\
\text { 18/04/2020) }\end{array}$ & Pictures only \\
\hline 4 & $\begin{array}{c}\text { Gulfnews.com world Americas (2020) Covid-19 virus accidentally leaked by an intern at Wuhan lab: US media. } \\
\text { Available at: https://gulfnews.com/world/americas/covid-19-virus-accidentally-leaked-by-an-intern-at-wuhan-lab- } \\
\text { us-media-1.1587122371639 (Accessed on 18/04/2020) }\end{array}$ & No \\
\hline 5 & $\begin{array}{l}\text { Business Insider coronavirus (2020) An unsubstantiated theory suggests the coronavirus accidentally leaked from a } \\
\text { Chinese lab - here are the facts. Available at: https://www.businessinsider.com/theory-coronavirus-accidentally- } \\
\text { leaked-chinese-lab-2020-4(Accessed on 18/04/2020) }\end{array}$ & Yes \\
\hline
\end{tabular}




\begin{tabular}{|c|c|c|}
\hline 6 & $\begin{array}{c}\text { Arab news world (2020) Did this Chinese government lab in Wuhan leak the coronavirus? Available at: https://www. } \\
\text { arabnews.com/node/1660561/world(Accessed on 19/04/2020) }\end{array}$ & No \\
\hline 7 & $\begin{array}{c}\text { Taiwan news world (2020) Photo reveals warped seal on Wuhan lab freezer door, China Daily photo of poor sealing } \\
\text { goes viral as suspicions mount over safety measures at Wuhan virology lab. Available at: https://www.taiwannews. } \\
\text { com.tw/en/news/3919496(Accessed on 19/04/2020) }\end{array}$ & No \\
\hline 8 & $\begin{array}{c}\text { MSNBC News corona virus (2020) Laboratory in Wuhan breaks silence to deny claims that the coronavirus originated } \\
\text { there. Available at: https://www.nbcnews.com/news/world/laboratory-wuhan-breaks-silence-deny-claims- } \\
\text { coronvarius-originated-there-n1186856(Accessed on 19/04/2020) }\end{array}$ & No \\
\hline
\end{tabular}

\section{Results}

Upon reviewing the 8 News Articles specially to collect the evidence only two articles provide the picture and documented evidence that may be accidentally in the Wuhan laboratory the studied novel corona virus got out of laboratory. Multiple sources are telling Fox News today that the United States now has high confidence that while the coronavirus is a naturally occurring virus it emanated from a virology lab in Wuhan that. Because of lax safety protocols an intern was infected who later infected her boyfriend and then went to the wet market in Wuhan where it then began to spread. (The Straits Times World, 2020). Scientists have been trying to understand the origin of COVID-19 and the virus that causes it SARS-CoV2.Originally scientists believed the virus may have developed in bats, and later pangolins. However, genomic comparisons suggest that the SARS-Cov-2 virus is the result of a recombination between two different viruses meaning the exact origin of the virus is still unclear (The World Economic Forum, 2020). In the space of a few weeks we have all learned a lot about COVID-19 and the virus that causes it SARS-CoV-2. But there have also been a lot of rumours and while the number of scientific articles on this virus is increasing there are still many grey areas as to its origins [22-24].

In which animal species did it occur? A bat, a pangolin or another wild species. Where does it come from? From a cave or a forest in the Chinese province of Hubei or elsewhere. In December 2019,27 of the first 41 people hospitalized (66\%) passed through a market located in the heart of Wuhan city in Hubei province. But according to a study conducted at Wuhan Hospital the very first human case identified did not frequent this market (The World Economic Forum, 2020). Defense Secretary Mark Esper told a reporter on thursday that it appeared the rise of COVID-19 was "natural" and "organic" contradicting some claims that China may have engineered the virus. However, that does not rule out the possibility that it could have emerged accidentally from the laboratory where diseases in bats were being studied a theory US intelligence agency are now looking into NBC News reported (Arab news world, 2020).

\section{Discussion}

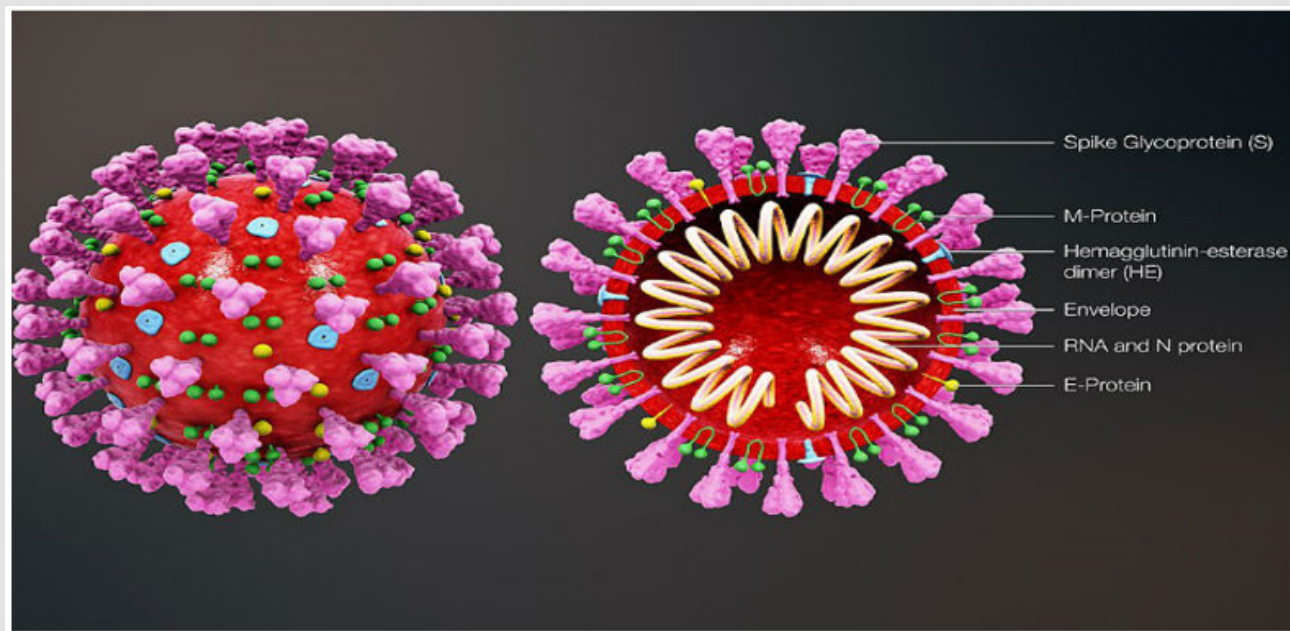

Figure 6: (Thepharmaletter, 2020): The Novel corona COVID - 19 Virus.

Documents detail early efforts by doctors at the lab and early efforts at containment. The Wuhan wet market initially identified as a possible point of origin never sold bats. The sources tell Fox News that blaming the wet market was an effort by China to deflect blame from the laboratory along with the country's propaganda efforts targeting the US and Italy (Fox KTVU, 2020).US Embassy officials warned in January 2018 about inadequate safety at the
Wuhan Institute of Virology lab and passed on information about scientists conducting risky research on coronavirus from bats The Washington Post reported Tuesday. Americans were originally helping train the Chinese in a program called prevent well before the Chinese started working on this virus. The French government helped the Chinese set up the Wuhan lab. China 100 percent suppressed data and changed data, samples were destroyed, 
contaminated areas scrubbed, some early reports erased, and academic articles stifled (Fox KTVU, 2020) (Figure 6). There is solid evidence based on genetic analysis from scientists in multiple countries that the COVID-19 pandemic resulted from a natural spill over event with the coronavirus most likely jumping from bats to people perhaps via an intermediate animal species. What we have less evidence about is where that spill over event happened (Bulletin of the Atomic Scientist, 2020).

While many scientists believe that the coronavirus first infected humans in nature or through the wildlife trade others think an accident could have occurred during the course of scientific research on coronaviruses or the animals that harbor them. Shi's team from the Wuhan Institute of Virology didn't just collect bat viruses during fieldwork. It also collected blood samples from more than 200 residents in villages close to one of the bat caves they'd been harvesting viruses from. They found that 3 percent had antibodies against SARSlike coronaviruses suggesting that nearby villagers had been infected by the bats despite not displaying SARSlike or other pneumonia like symptoms. Bats fly out every night over their houses one of the researchers explained some of them shelter from rain in caves or collect guano for fertilizer (Bulletin of the Atomic Scientist, 2020) (Figures $7 \&$ 8). Authorities at the Wuhan CDC first informed the World Health Organization about an unknown pneumonialike illness on December 31. They reported that most of the 41 cases first detected were among handlers and frequent visitors of the Huanan market which was shut down January 1.

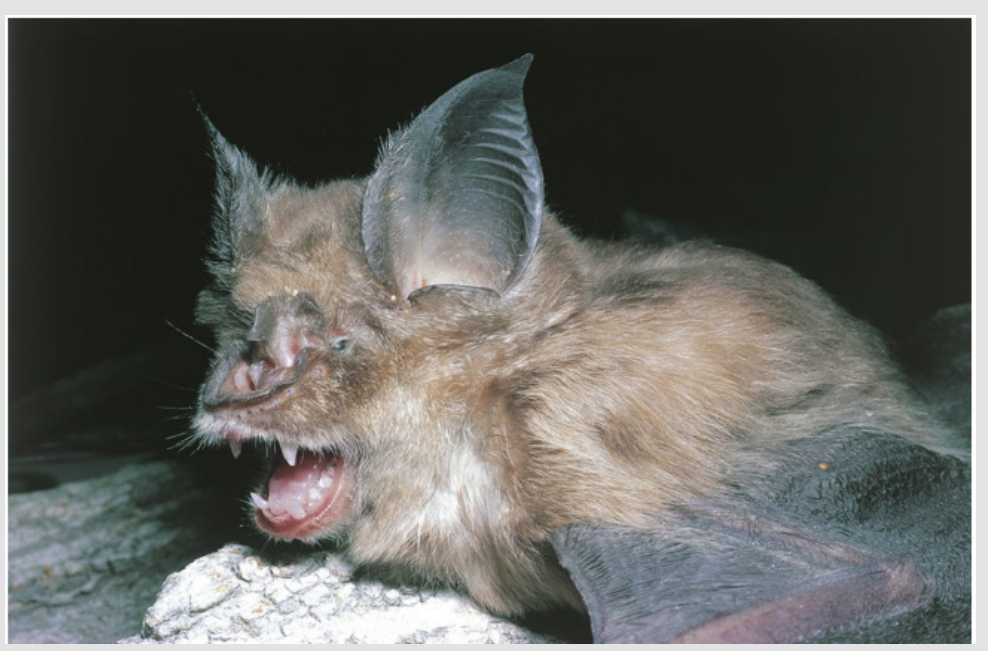

Figure 7: Business Insider coronavirus, 2020): A greater horseshoe bat, a relative of the Rhinolophis sinicus bat.

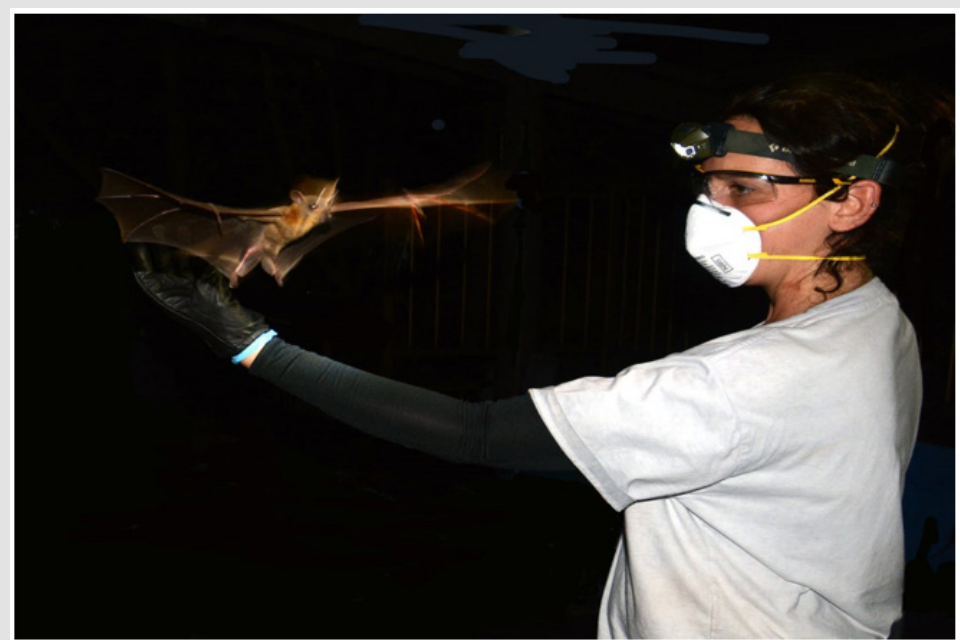

Figure 8: Business Insider coronavirus, 2020): A researcher with a bat.

A week later expert at the Wuhan Institute of Virology identified the new coronavirus and sequenced its genome the disease it causes was later named COVID-19.Much of the theory about a lab leak is based on the proximity of those research labs the Wuhan CDC and the Institute of Virology to the Huanan Seafood Wholesale Market the wet market previously thought to be the outbreak's origin point. That's because a non-peer-reviewed paper which was retracted cited the market's proximity to two labs. The paper's author Botao Xiao of the South China University of Technology previously worked in Wuhan (Business Insider coronavirus, 2020). Trump and Pompeo said they would investigate reports the Chinese mishandled the COVID-19 virus and mentioned the possible role 
of the Wuhan Institute for Virology. Pompeo told Fox Business on Friday It's not political and this is about science and epidemiology. In a national radio interview earlier this week he said we know they have this lab we know about the wet markets. We know that the virus itself did originate in Wuhan, so all those things come together (Arab news world, 2020).

China disputes that the virus could have originated in the Wuhan lab. Foreign Ministry spokesperson Zhao Lijian said Thursday that the head of the World Health Organization had repeatedly said there's no evidence the virus was made in a lab and that many wellknown medical experts in the world also think that the statement of so called laboratory leaks is without scientific basis. The Wuhan virology lab has actively worked with the WHO and other United Nations bodies said Yuan handing over the genome sequence and laying the foundation for other countries to prepare testing and vaccines (MSNBC News corona virus, 2020).

\section{Conclusion}

By looking at the results of the data table, data analysis and diagrammatic presentation $25 \%$ of the News articles provides some evidence and $75 \%$ of the news articles did not provide any evidence. The evidence we are looking at that Wuhan laboratory is clearly responsible for accidentally leaking the novel corona virus COVID-19 in the community.

\section{References}

1. (2020) The Straits Times World. Coronavirus pandemic: US pursues theories that virus leaked from Wuhan lab, China.

2. (2020) LiveMint e-paper (2020) Covid-19 virus accidentally leaked by an intern at Wuhan lab suggests US media, India.

3. (2020) Mirror Coronavirus news. Photos inside Wuhan lab show broken seal on unit containing bat coronavirus.

4. (2020) Gulfnews.com world Americas. Covid-19 virus accidentally leaked by an intern at Wuhan lab: US media, USA.

5. (2020) Business Insider coronavirus. An unsubstantiated theory suggests the coronavirus accidentally leaked from a Chinese lab - here are the facts.

6. (2020) The pharma letter. US/Indian collaboration on vaccine against COVID-19, London.

7. (2020) Arab news world. Did this Chinese government lab in Wuhan leak the coronavirus, Saudi Arabia.

ISSN: 2574-1241

DOI: 10.26717/BJSTR.2020.27.004575

Ahsan Ali Siddiqui. Biomed J Sci \& Tech Res

This work is licensed under Creative

Commons Attribution 4.0 License

Submission Link: https://biomedres.us/submit-manuscript.php
8. (2020) Taiwan news world (2020) Photo reveals warped seal on Wuhan lab freezer door, China Daily photo of poor sealing goes viral as suspicions mount over safety measures at Wuhan virology lab, Taiwan.

9. (2020) MSNBC News corona virus (2020) Laboratory in Wuhan breaks silence to deny claims that the coronavirus originated there, USA.

10. Ahsan Ali Siddiqui (2019) Accessing Confidential Health Information by Mobile Devices the Trend of Online Treatment and Use of Social Media for Health Services. Biomed J Sci \& Tech Res 15(5).

11. IBM (2006) IBM SPSS Software, USA.

12. FeiYu, Lanying Du, David Ojcius (2020) Measures for diagnosing and treating infections by a novel coronavirus responsible for a pneumonia outbreak originating in Wuhan, China. ELSEVIER Microbes and infection 22 (2): 74-79.

13. Chen Ze Liang, Zhang Qi, LuYi, Zhong M, Yi L, et al. (2020) Distribution of the COVID-19 epidemic and correlation with population emigration from Wuhan, China. Chinese Medical Journal 133(9): 1044-1050.

14.(2020) France 24. Pompeo says 'enormous evidence' coronavirus originated in Wuhan lab, France.

15. (2020) The sun UK. LAB COVER UP Pics of Wuhan scientists handling bats with shocking lack of safety precautions are deleted from institute's website, UK

16. (2020) Evidence SARS COV-2. Evidence SARS-CoV-2 Emerged from a Biological Laboratory in Wuhan, China.

17. (2020) Global times china. Wuhan virology institute draws suspicion and doubt amid COVID-19 outbreak, China.

18. (2020) BBC News US and Canada. Coronavirus: US to halt funding to WHO, says Trump, Canada.

19. Cronin P, Ryan F, Coughlan M (2008) Undertaking a literature review a step-by-step approach. BJN British Journal of Nursing 17(1): 38-43.

20. Wakefield A (2015) Synthesizing the literature as part of a literature review. Nursing Standard 29(29): 44-51.

21. Katharina Schmidt, Ines Aumann, Ines Hollander, Kathrin Damm,J Matthias Graf von der Schulenburg (2015) Applying the Analytic Hierarchy Process in healthcare research: A systematic literature review and evaluation of reporting. BMC Medical Informatics and Decision Making 15: 112

22. The World Economic Forum COVID Action Platform (2020) Coronavirus origins: genome analysis suggests two viruses may have combined, Switzerland.

23. Fox KTVU (2020)Sources believe COVID-19 originated in Wuhan lab as part of China's efforts to compete with US, USA.

24. Bulletin of the Atomic Scientist (2020)Natural spillover or research lab leak? Why a credible investigation is needed to determine the origin of the coronavirus pandemic, Taylor and Francis.

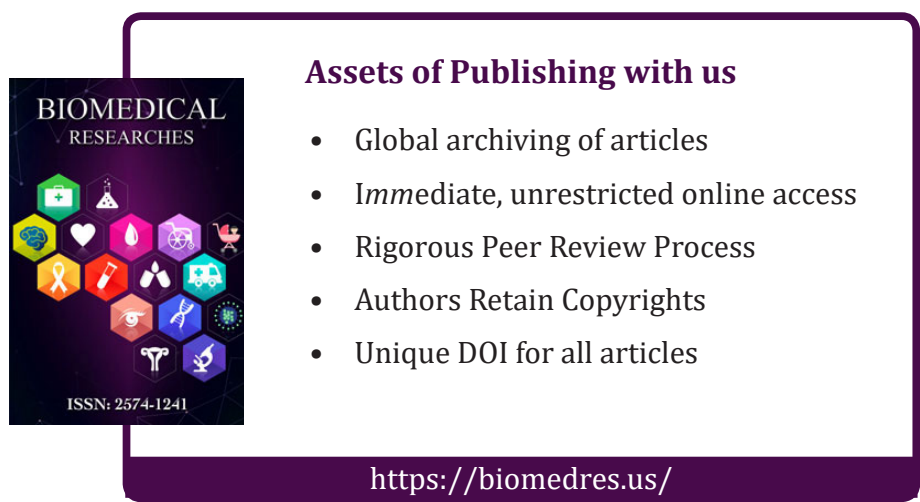

